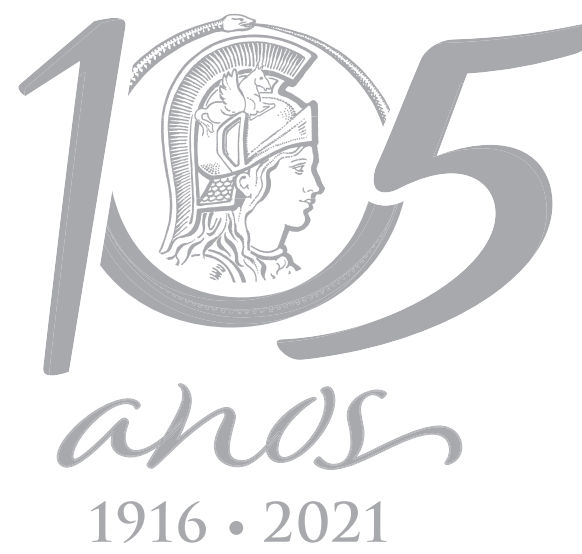

\title{
Morphological diversity and discrimination tools of the non-marine ostracod Cypridopsis silvestrii across temporal and spatial scales from Patagonia
}

\author{
LORENA Y. RAMOS, ALEJANDRA PATRICIA PÉREZ, CORINA A. COVIAGA, ANTJE \\ SCHWALB, DANIEL ARIZTEGUI, MARTA ALPERIN \& GABRIELA C. CUSMINSKY
}

\begin{abstract}
Geometric morphometric methods are powerful tools to discriminate between closely related ostracods taxa as well as to study the relationship between their morphological variations, taxonomy and paleoecology. In this study, valve outline analysis allows the discrimination between the non-marine ostracod C. silvestrii and $R$. whatleyi juveniles, pointing out differences in the posterior valve area and surface ornamentation. Modern female specimens of $C$. silvestrii from 23 sites located in a spatial transect (41 to $51^{\circ} \mathrm{S}$ ) exhibited extensive morphological variability, on the basis of which three morphotypes (acuminated, transitional, subtruncated) were determined. Multivariate analyses showed that acuminated and transitional shapes are not arranged in groups but the subtruncated morphotype, previously described as E. cecryphalium, seems to be associated with low water conductivity $\left(372 \mu \mathrm{S} \mathrm{cm}^{-1}\right)$, dominant cold (5 으) and windy (8.6 $\mathrm{m} \mathrm{s}^{-1}$ ) climatic conditions. The fossil cluster which included nine cores spanning the last $15.6 \mathrm{kyr}$, only covered acuminated and transitional shapes, which may indicate that these lineages might be older than the subtruncated morphotype. In addition, morphological differences between reproduction modes suggested that parthenogenetic females exhibit de posterior margin more acuminate than sexual females. These results set the ground for more precise ecological and paleoenvironmental studies in Patagonia.
\end{abstract}

Key words: Cypridopsis silvestrii, morphological variability, Ostracoda, Patagonia, valve outline analysis.

\section{INTRODUCTION}

The study of the form (shape and size) and quantitative descriptions of the shell morphology of diverse aquatic invertebrates has already shown to have substantial implications to the taxonomy, functional morphology, phenotypic plasticity, ecology and biogeography. Geometric morphometric methods (Adams et al. 2004) have further proven to be powerful tools to describe and compare fossil and modern shells of various taxonomic groups. Specifically, they objectively discriminate between close taxa and characterize intraspecific variation and its possible causes (e.g. Monferran et al. 2013, Mazzini et al. 2014, Aguirre et al. 2015, Bayer et al. 2016). Ostracods (Class Ostracoda), are small crustaceans with a low-magnesium calcite bivalve carapace ("hard parts") that totally encloses the body and appendages ("soft parts") (Meisch 2000). Morphometric analysis allows relating the range of their valve morphologies with reproduction mode and sex (Wrozyna et al. 2014, Pérez et al. 2019), growth stage (Baltanás et al. 2000, Danielopol et al. 2008) and even with environmental conditions 
and genetic characteristics of the populations (Baltanás \& Geiger 1998, Wrozyna et al. 2018b). Based on their environmental sensibility and often excellent preservation in lake sediments, ostracods are biological proxies widely used to interpret past limnological, environmental and climatic changes (Griffiths \& Holmes 2000). For that reason the precise identification of species as well as the knowledge of their morphological variability and ecological preferences are critical to the successful use of ostracods in paleoenvironmental and climatic reconstructions (Mezquita et al. 2005, Coviaga et al. 2018a, Ramos et al. 2019).

The Argentinean part ofPatagonia in southern South America has a broad environmental heterogeneity and is particularly interesting for paleoclimatic reconstructions (Kilian \& Lamy 2012). The study of ostracods in this region started at the beginning of the $20^{\text {th }}$ century and mostly focused on paleoenvironmental reconstructions. Further research dealing with taxonomical descriptions, ecological requirements and intraand interspecific morphological variability have increased in the last decades (Cusminsky \& Whatley 1996, Schwalb et al. 2002, Cusminsky et al. 2005, Ramón-Mercau et al. 2012, 2014, Coviaga et al. 2018 a). Geometric morphometric methods have also been successfully applied to analyse phenotypical changes in the carapace along a wide environmental range and Quaternary sequences (Ramos et al. 2015, 2017, 2019, Coviaga et al. 2018b, Pérez et al. 2019). These results provided new insights to determine the role of factors triggering morphological trends while improving our knowledge about taxonomy, ecology and morphological traits of ostracod species in Patagonia. Applying these methods and comparative analysis of limb morphology, Coviaga et al. (2018b) reassigned Patagonian Eucypris fontana (Graf 1931) to genus Riocypris as Riocypris whatleyi, enabling an accurate determination of the taxonomic status with ample paleolimnological significance. Subsequently, Pérez et al. (2019) proposed a new taxonomical combination of Cypridopsis silvestrii (Daday 1902) based on the analysis of living fauna from northern and southern Patagonia environments. In the same taxonomic study, individuals originally described as juveniles of E. fontana (now R. whatleyi) from previous paleoenvironmental reconstructions from Los Juncos (Cusminsky \& Whatley 1996) and El Toro lakes (Coviaga et al. 2017) and as Eucypris cecryphalium (Cusminsky et al. 2005) from Lake Cerro Frías (Ramón-Mercau et al. 2012), were reassigned to C. silvestrii. These misidentifications were probably due to the fact that $C$. silvestrii is a species of small size, pedomorphic shape and shows considerable morphological variability. Indeed, previous morphometric analysis by Pérez et al. (2019) applied to C. silvestrii from two living populations, i.e. El Toro and El Sello, with distinct modes of reproduction (sexual and parthenogenesis), shows a considerable morphological plasticity of valves. Also, the species has a wide geographical range, inhabits a broad variety of environments and is part of the subfossil sedimentary record in Patagonia Argentina (Pérez et al 2019). Therefore, this scenario provides a good opportunity to apply geometric morphometric methods to discriminate between these taxa while evaluating valve morphological variability along both broad environmental and temporal ranges.

In this contribution, we use outline-based morphometric analysis to test this method for discriminating between problematic identification taxa i.e. taxa that visually are similar, using specimens of $R$. whatleyi juveniles, E. cecryphalium and C. silvestrii. In particular, the aims of this study are to provide confident tools for the correct identification of $C$. silvestrii 
based in its hard parts by (1) investigating its morphological variability along both a spatial transect ( 41 to $51^{\circ} \mathrm{S}$ ) within a broad climatic gradient mainly related to precipitation patterns as well as (2) temporal distribution from the Late Pleistocene to present. The taxonomic, ecological, biogeographical and paleoenvironmental implications of its morphological variability are also discussed.

\section{MATERIALS AND METHODS}

\section{Regional setting And study area}

Patagonia is a cold temperate region in southern South America ranging from about $36-55^{\circ} \mathrm{S}$ and covering an area of approximately $770,000 \mathrm{~km}^{2}$ (Mazzoni \& Rabassa 2018). Its large latitudinal and longitudinal extension guarantees a wide range of climatic conditions and environmental heterogeneity. The climate is mainly ruled by the presence of the Andean Mountains, anticyclones of the Pacific and Atlantic oceans, and strong and constant West winds (Southern Westerlies) (Paruelo et al. 1998). The effective moisture is predominantly driven by the strength and latitudinal position of the Southern Westerlies and the orographic effects of the Andes mountains which determine a WestEast precipitation gradient from 4000 mm/y to $120 \mathrm{~mm} / \mathrm{y}$, concentrated mainly during the Austral winter (May-August) (Paruelo et al. 1998, Villalba et al. 2003). South of $52^{\circ} \mathrm{S}$ the average altitude of the Andean range is lower while losing continuity, thus the rain shadow effect diminishes (Coronato et al. 2008). Because of the high wind velocities reaching a maximum in spring, the wind chill effect is an important bioclimatic factor (Coronato et al. 2008). The mean annual temperature ranges from $12{ }^{\circ} \mathrm{C}$ in the northeastern part to $3^{\circ} \mathrm{C}$ towards the south because isotherms have a northeast-southwest distribution due to the combined effect of latitude and altitude (Paruelo et al. 1998).

The study area covers at least 400,000 $\mathrm{km}^{2}$ of Patagonia comprising modern and fossil records containing $C$. silvestrii from the Late Pleistocene to the present (Figure 1). To review and update the actual distribution of C. silvestrii in Patagonia, Argentina, samples collected from 114 sites including streams, small ponds, wetlands and large lakes, during four field campaigns between 2002 to 2018 were reexamined (see Schwalb et al. 2002, Cusminsky et al. 2005, Ramos et al. 2017, Coviaga et al. 2018a, c, Pérez et al. 2019). In addition, a dataset of 26 modern sites from southern Patagonia was also considered (Ramón-Mercau \& Laprida 2016).

\section{Material}

The targeted species was found in Quaternary and modern environments from 47 sites in the Argentinean Patagonia including sediment and water samples (Supplementary Material - Table SI). We refer to modern specimens to those individuals sampled alive or recovered from surficial sediments. We especially investigated individuals identified initially as E. fontana juveniles and specimens described as E. cecryphalium. Selected specimens (valves and carapaces) were also examined and photographed under Scanning Electron Microscope (SEM) (Phillips SEM 515, CNEA Bariloche, Argentina).

A subset of 351 well-preserved valves from 23 modern sites and nine Quaternary sequences were analysed by morphometric methods. This morphological dataset represents the $68 \%$ of the total sites $(n=47)$ with presence of $C$. silvestrii so far registered in this work and in the literature (Supplementary Material - Table SI). In order to test for shape differences between $C$. silvestrii and $R$. whatleyi juveniles and to compare with those individuals without available soft 


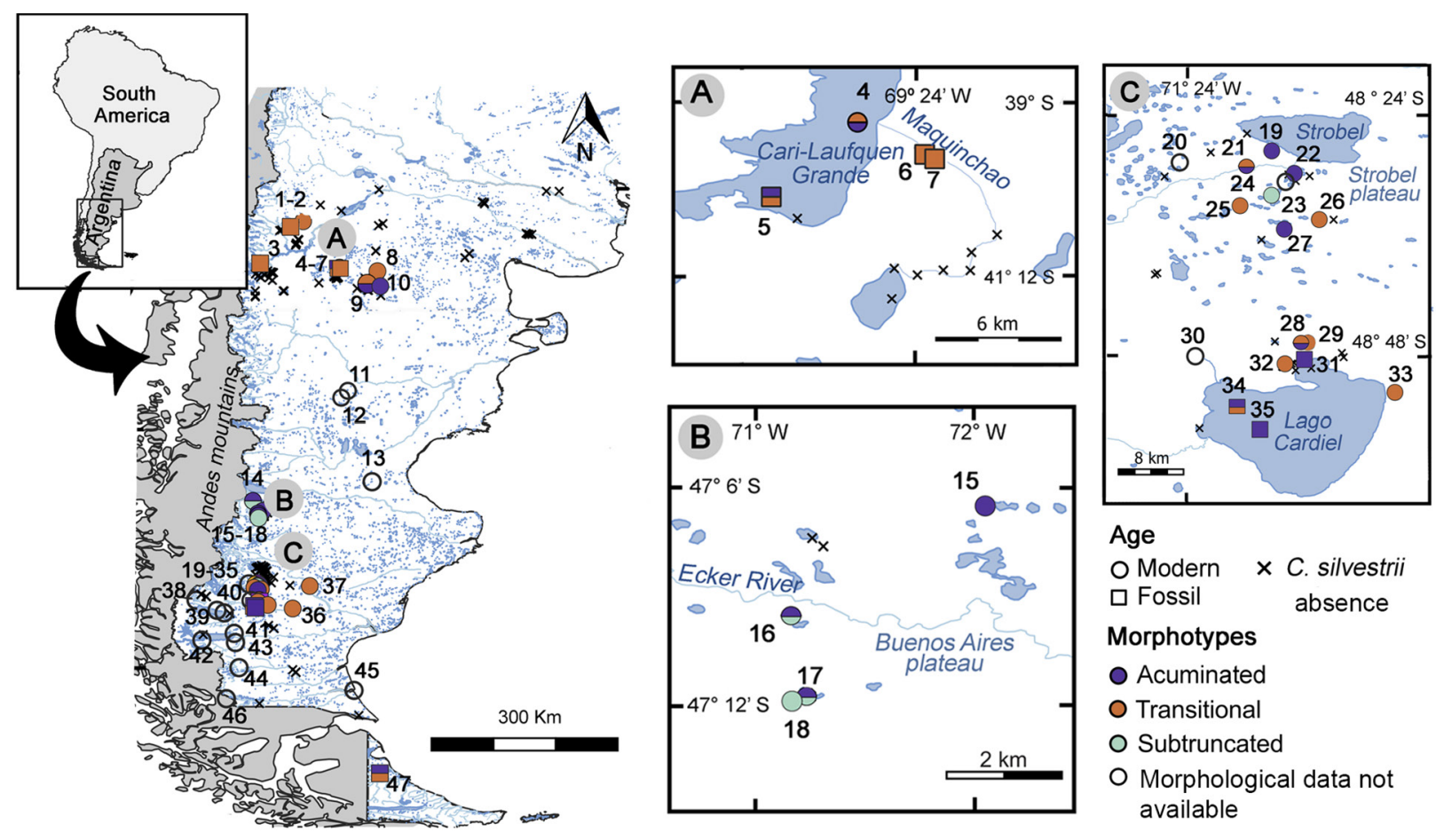

Figure 1. Location of 47 sampling sites showing the occurrences of Cypridopsis silvestrii in Patagonia. Morphotype and age of specimens are also indicated. For details of number information see Supplementary Material - Table SI.

parts, this morphological dataset included the holotype and paratype left valves from living specimens of adult $C$. silvestrii recovered from El Toro $(E T=40)$ and El Sello (ES = 20) lakes used in the taxonomic study by Pérez et al. (2019). Moreover, living (ET, $n=20$ ) and fossil (ETC, $n$ = 25) A-3 juvenile stage of $R$. whatleyi from ET were added. We chose stage A-3 of $R$. whatleyi because these juveniles had a similar size to adults of $C$. silvestrii (C. silvestrii adults from $\mathrm{ET}$, mean length $\pm S D=664 \pm 19 \mu \mathrm{m} ; \mathrm{A}-3$ juvenile of $R$. whatleyi from $\mathrm{ET}$, mean length $\pm \mathrm{SD}=725$ $\pm 28 \mu \mathrm{m})$ and therefore, they are more likely to be mistaken for $C$. silvestrii. Secondly, in order to study similarities between E. cecryphalium and $C$. silvestrii, the holotype and paratype of E. cecryphalium from Las Encadenadas (LE) pond (Cusminsky et al. 2005), including valves and remains of soft parts, were added to the morphological dataset to the analysis. Besides, a valve previously assigned to E. cecryphalium from Lake Cerro Frías (CFI) was digitalized from the literature (Figure 4, 3 in Ramón-Mercau et al. 2012) and included in the analysis. The holotype and paratype living specimens of $C$. silvestrii recovered from El Toro (ET) (Pérez et al. 2019) were integrated and compared.

\section{Morphological data acquisition}

All well-preserved valves were separated, counted and grouped according to body size and gender. Sex determination was done only in the case of those individuals with preserved softparts and visible reproductive organs. Valves were photographed in external lateral view against translucent background with a digital camera (AmScope MD500) fitted to a standard light microscope (Olympus BX40, BX50) at a magnification of 40x. Size variations, maximum length and height $(\mu \mathrm{m})$ were measured for each valve on digital images using Image-Pro software (Supplementary Material - Figure S1). 
In order to obtain as much morphological and biogeographical information as possible and because no significant asymmetries between the left and right valves were found (Supplementary Material - Table SII), we used in our analyses both the left and right valves. Images of right valves were reflected in Photoshop CS6 in order to get just one valve orientation because this procedure is a necessary step prior to morphological analysis.

The pictures of the valves were processed using TpsDig software (Rohlf 2010) which digitize outlines. Then, for the reconstruction of valve outlines, we applied the Linhart's B-spline algorithm implemented in the Morphomatica software v1.6 (Neubauer \& Linhart 2008, Linhart et al. 2007). This method fits elementary polynomial curves to the valve outline, with each curve is defined by its corresponding control points. To describe the outline of each specimen, valve outlines were approximated in Morphomatica using the command for 32 control points (16 dorsal and 16 ventral) (Supplementary Material - Figure S1). Finally, the shape differences between any two outlines were estimated as the area deviation using Morphomatica, which is the area 'between' the outlines, when valves are superimposed after being normalized for position, rotation and size (outline size was normalized to unit area) (Neubauer \& Linhart 2008).

\section{Environmental and climatic variables}

The following environmental variables were included in the analyses: electrical conductivity $\left(\mu \mathrm{S} \mathrm{cm}^{-1}\right), \mathrm{pH}$, temperature $\left({ }^{\circ} \mathrm{C}\right)$ and dissolved oxygen concentration ( $\mathrm{mg} \mathrm{L}^{-1}$ ) of host waters. Additionally, climatic variables were added to the local environmental conditions. Annual mean wind speed $\left(\mathrm{m} \mathrm{s}^{-1}\right)$ and the 19 bioclimatic variables were extracted from the WorldClim v.2 database (Fick \& Hijmans 2017). These climatic variables were obtained at the spatial resolution of 30 seconds (approximately $1 \times 1$ $\mathrm{km}$ per pixel), which is an adequate coarse resolution to detect climate influence in species distribution (Pearson \& Dawaon 2003). Single non-parametric correlations tests (Spearman rank) were performed to explore the relationship among the environmental and climatic variables using the package 'corrplot' (Wei \& Simko 2017, $\mathrm{R}$ Core Team 2019). The final set of variables chosen consisted of electrical conductivity, $\mathrm{pH}$, water temperature and dissolved oxygen concentration, annual mean wind speed (Wind), mean annual temperature (Bio 1 or MAT), mean annual precipitation (Bio 12 or MAP) and precipitation seasonality (coefficient of variation, Bio 15).

\section{Morphological and statistical analysis}

\section{Taxonomic considerations}

Based on area deviation, the matrix of pairwise dissimilarities including all living and fossil valve outlines of $C$. silvestrii from 31 sites ( $n=322), E$. cecryphalium from LE $(n=29)$ Supplementary Material - Table SI) and A-3 R. whatleyi juvenile (ET $=20$ and $\mathrm{ETC}=25$ ) was analysed with nonMetric Multidimensional Scaling ( $n$-MDS) in order to investigate interspecific valve shape variability. A valve of E. cecryphalium digitalized using a scanned SEM photograph from the literature (Figures 4, 3 in Ramón-Mercau et al. 2012) was also added to the n-MDS (Supplementary Material - Table SI). The statistical differences in valve shape between (1) holotype and paratype individuals of $C$. silvestrii from Lake ET and the A-3 juvenile stage of $R$. whatleyi, and (2) between C. silvestrii from ET and holotype and paratype individuals of E. cecryphalium from LE pond were tested by performing One-Way ANOSIM Pairwise Test (Clarke \& Warwick 2001). ANOSIM 
is a non-parametric test useful to differentiate groups in a multivariate context, where the value of the R statistic measure indicates the degree of separation of groups. It is approximately 0 when there is no separation between samples and 1 when samples are completely separated (Clarke \& Warwick 2001). In addition, for shape comparison a virtual mean outline (consensus shape) for each species, $R$. whatleyi, C. silvestrii and E. cecryphalium, were computed using the Morphomatica software.

\section{Morphological variability}

Firstly, a cluster analysis of unweighted pair group mean averages (UPGMA) was performed on the obtained pairwise resemblance matrix using the area deviation, of the modern specimens previously assigned to adults of $C$. silvestrii ( $n=$ 116 individuals). These results allowed assessing the morphological variability of $C$. silvestrii as well as to explore the morphological groups across all modern sites. Additionally, statistical differences in valve shape between morphotypes were tested by performing an ANOSIM. Males were only used to evaluate sexual dimorphism at each site also by ANOSIM. Additionally, size differences between sexes and morphotypes were evaluated using Kruskal-Wallis tests (Statistica v.7, StatSoft, Inc. 2004). Secondly, a non-metric multidimensional scaling ( $n$-MDS), including both the modern valves and those previously assigned to $C$. silvestrii in the sedimentary sequences, was done to compare dissimilarities in valve shape between modern and fossil specimens. All multivariate statistical analyses applied on the dissimilarity outline matrix representing the pairwise distances given by the area deviation, were carried out with PRIMER 6 software (Clarke \& Gorley 2006).

\section{Distribution and ecological preferences of $\mathrm{C}$. silvestrii and its morphotypes}

The environmental tolerance index (ETI), ecological tolerance $\left(t_{k}\right)$ and optimum $\left(u_{k}\right)$ values of the species and morphotypes for environmental and climatic variables were calculated by weighted-averaging (WA) using the rioja package (Juggins 2017, R Core Team 2019). To update the ecological preferences of $C$. silvestrii, all sites with presence of this species were considered, including those cited in the bibliography (see Supplementary Material Table SI). However, only populations with living specimens were pondered to calculate local environmental preferences. Optimum values have been obtained by calculating the weighted averaging of the values of the environmental and climatic variables in the samples where species and morphotypes were present. ETI index was used to calculate relative tolerance ranges of ostracod species for different environmental and climatic variables from the formula $\mathrm{ETI}=$ (range of $X$ species) / (range of $X$ dataset) (Curry 1999). Accordingly, ETI ranges from zero indicate no tolerance to one, higher tolerance.

Principal Component Analysis (PCA) was applied using the Canoco software to summarize the most important environmental and climatic gradients along the sites (Canoco 5, Leps \& Smilauer 2003). From a total of six variables were used for the PCA after eliminating strongly correlated and not well represented variables. Climatic and local environmental variables were centred and standardized prior to ordination analysis. The occurrence of morphotypes in each site was indicated for illustrative and descriptive purposes. 


\section{RESULTS}

\section{Taxonomic considerations}

The n-MDS plot, that exhibits the overall valve shape variation, shows a clear shape separation between A-3 juvenile stages of $R$. whatleyi and adults of $C$. silvestrii from Lake ET (Figure 2a). Moreover, there were statistically significant differences of valve shape between these species (ANOSIM $R_{\text {global }}=1 ; p=0.1 \%$ ). The main differences in valve outline between $R$. whatleyi juvenile and adults of $C$. silvestrii are found in the posterior area, which is more pointed in the juvenile stage of $R$. whatleyi than in adults of $C$. silvestrii (Figure $2 b$ ). In addition, $C$. silvestrii has the antero-dorsal margin straight whereas that of $R$. whatleyi is more rounded. On the other hand, R. whatleyi juvenile has a longitudinal ribbing ornamentation especially in the posterior margin (Figure 3a-c) whereas adults of $C$. silvestrii have a surface reticulation and, in general, abundant setae (e.g. Figure 3 n, p and $r$ ). Both species present wart-like elevations in the anterior area of the valves (Figure 3). The n-MDS plot and ANOSIM, including recent and fossil specimens (Figure 2a, both solid and open symbols), evidence that it would be possible to discriminate between $R$. whatleyi juveniles and $C$. silvestrii using valve shape (ANOSIM $R_{\text {global }}$ $=0.884 ; p=0.1 \%)$. Therefore, some specimens previously described as $R$. whatleyi juveniles are in fact adults of $C$. silvestrii (Supplementary Material - Table SI).

Furthermore, based on the n-MDS plot, E. cecryphalium partially overlaps in the $C$. silvestrii morphospace (Figure $2 \mathrm{a}$ ). The $\mathrm{R}$ value a)

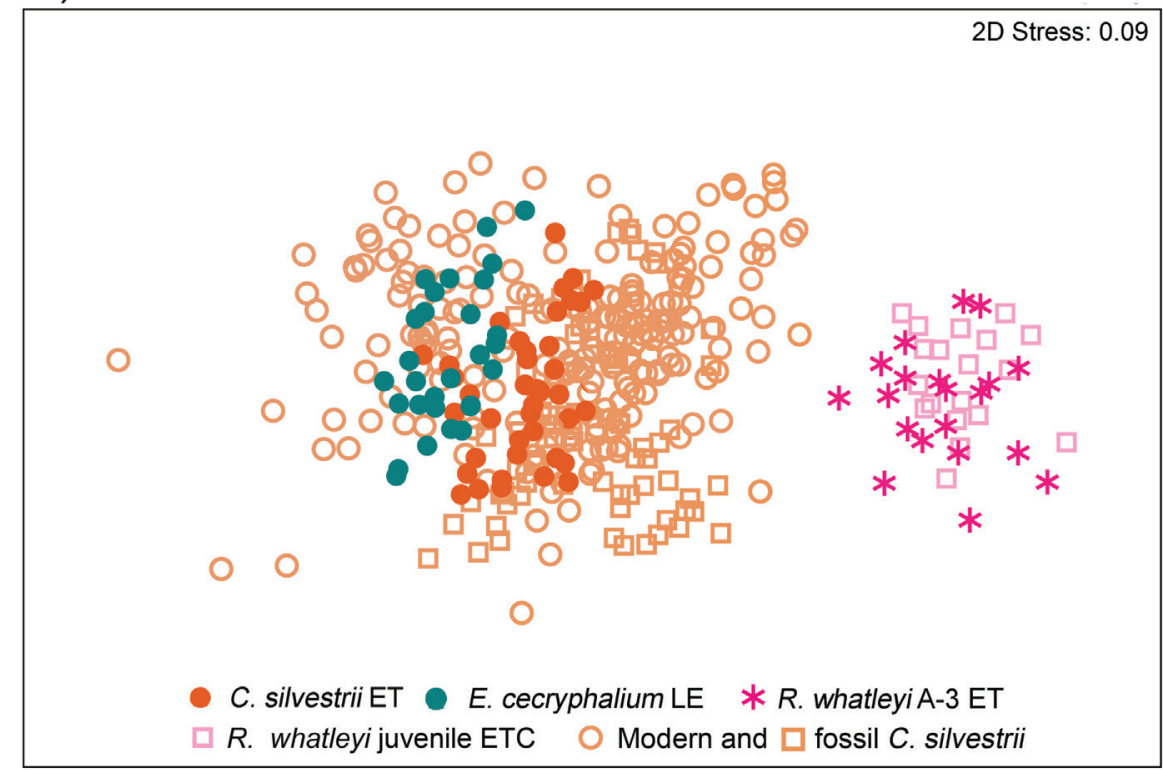

b)

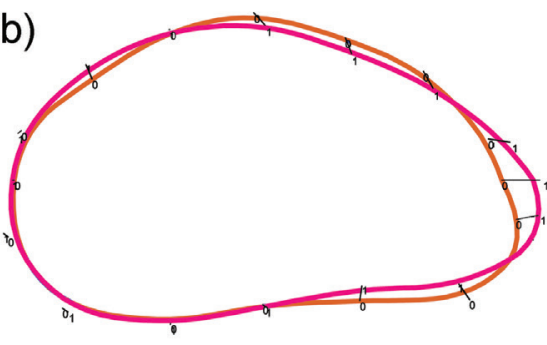

c)

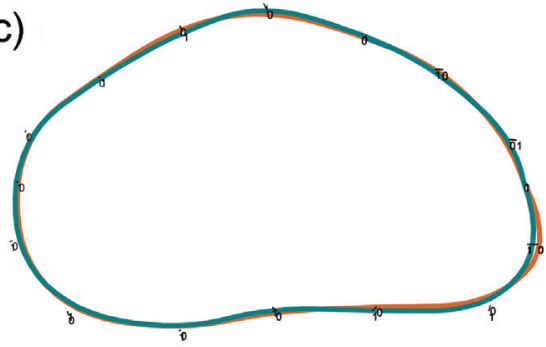

Figure 2. a) Non-metric Multidimensional Scaling (n-MDS) plot showing the shape dissimilarities between all digitized outlines (normalized for area) of C. silvestrii $(n=351)$ from 32 modern and fossil sites and $R$. whatleyi juvenile valves from Lake ET ( $\mathrm{n}=$ 20) and ET Core (ETC, $n=$ 25). Superimposition of the mean outline (consensus shape) in "normalized for area" mode of b) holotypes and paratypes of $C$. silvestrii females from Lake ET (0, orange line) and $R$. whatleyi juvenile, instar A-3 (1, pink line) and c) C. silvestrii females from Lake ET ( 0 , orange line) and holotypes and paratypes of E. cecryphalium (hereafter C. silvestrii) from LE pond (1, green line). 
(ANOSIM, $R_{\text {global }}=0.389 ; p=0.1 \%$ ) also points to partial overlapping between E. cecryphalium from LE pond and C. silvestrii from the Lake ET. Valves of E. cecryphalium from LE pond (Figure $3 \mathrm{i}$ and $\mathrm{j}$ ) have a more subrectangular outline in the posterior area than those of $C$. silvestrii (Figure $2 \mathrm{C}$ and Figure $3 \mathrm{l}$ ), and the body size of females from E. cecryphalium (mean \pm SD $\mu \mathrm{m}=$ $719 \pm 19$ ) is slightly larger than that of $C$. silvestrii females (mean $\pm \mathrm{SD}=664 \pm 18 \mu \mathrm{m}$ ). Moreover, the analysis of soft parts of E. cecryphalium from LE pond, especially the uropodal ramus strongly reduced and flagelliform in the females, indicate that analysed specimens do not belong to Eucypris. Therefore, given the set of observed morphological characters of hard and soft parts, we suggest that the specimens previously described as E. cecryphalium belong to C. silvestrii. Further details about differences in shape, size and ornamentation are given in the section presenting the morphological variability of $C$. silvestrii.

\section{Characterization of morphological variability through spatial and temporal scales}

Modern female $C$. silvestrii specimens exhibit a high degree of morphological variability, which was observed mainly in valve shape, size and surface ornamentation (Figure 3e-s). The dendrogram resulting from the cluster analysis based on outline valve similarities shows three principal groups or morphotypes (Figure 4). In the first group, denominated as "subtruncated" morphotype, which includes the valves from LE (originally described as E. cecryphalium), the more triangular shapes with the posteriordorsal margin subtrapezoidal to subtruncated were placed. In the second group, denominated as "transitional" morphotype, which includes the valves from $E T$, valves neither subtruncated nor acuminated, which had transitional shapes were placed, and, in the third cluster, the "acuminated" morphotype with more elongated valves and the posterior-dorsal area more acuminate were located (Figure 4a). These differences in valve shape between morphotypes were statistically significant (Figure 4b). Length and height also differ significantly between these morphotypes defined by the cluster (Kruskal-Wallis Test, length $\mathrm{H}_{2,216}=90.13$, height $\mathrm{H}_{2,216}=88.46, \mathrm{P}<$ 0.001; Figure 4C). Specifically, the subtruncated morphotype tends to have larger valves in length (mean $\pm \mathrm{SE}=733 \pm 3$ ) and height (mean \pm $\mathrm{SE}=440 \pm 2$ ) than the acuminated morphotype (length, mean \pm SE $705 \pm$ 4; height, mean \pm SE = $394 \pm 2$ ). The latter has a greater length (mean $\pm \mathrm{SE}=700 \pm 4$ ) and height (mean $\pm \mathrm{SE}=384 \pm$ 2) than the transitional ones (Kruskal-Wallis Test, multiple comparisons Z' values, $\mathrm{P}<0.05$ ). The three morphotypes have a surface valve ornamentation characterized by a delicate reticulation concentrically disposed at about the central area (Figure 3e-s). This ornamentation is more evident in the subtruncated morphotype (Figure 3e-k) which also has fewer setae than the transitional or acuminated morphotypes (Figure 3l-s). In relation to internal valve characteristics, the acuminated and transitional morphotypes (Figure 3, l and q) show a calcified inner lamella more developed and the selvage on the anterior margin more noticeable than the subtruncated morphotype (Figure $3 \mathrm{f}$ and $\mathrm{j}$ ).

Acuminated and transitional morphotypes of $C$. silvestrii occurred both in northern and southern Patagonia whereas subtruncated morphotype was collected in five lakes located in South Patagonia (Figure 1). This species was found both in populations consisted exclusively of females suggesting parthenogenetic populations, and with occurrence of males indicatingsexual reproduction (See Reproduction modes and sexual dimorphism section for more details). However, note that the subtruncated 

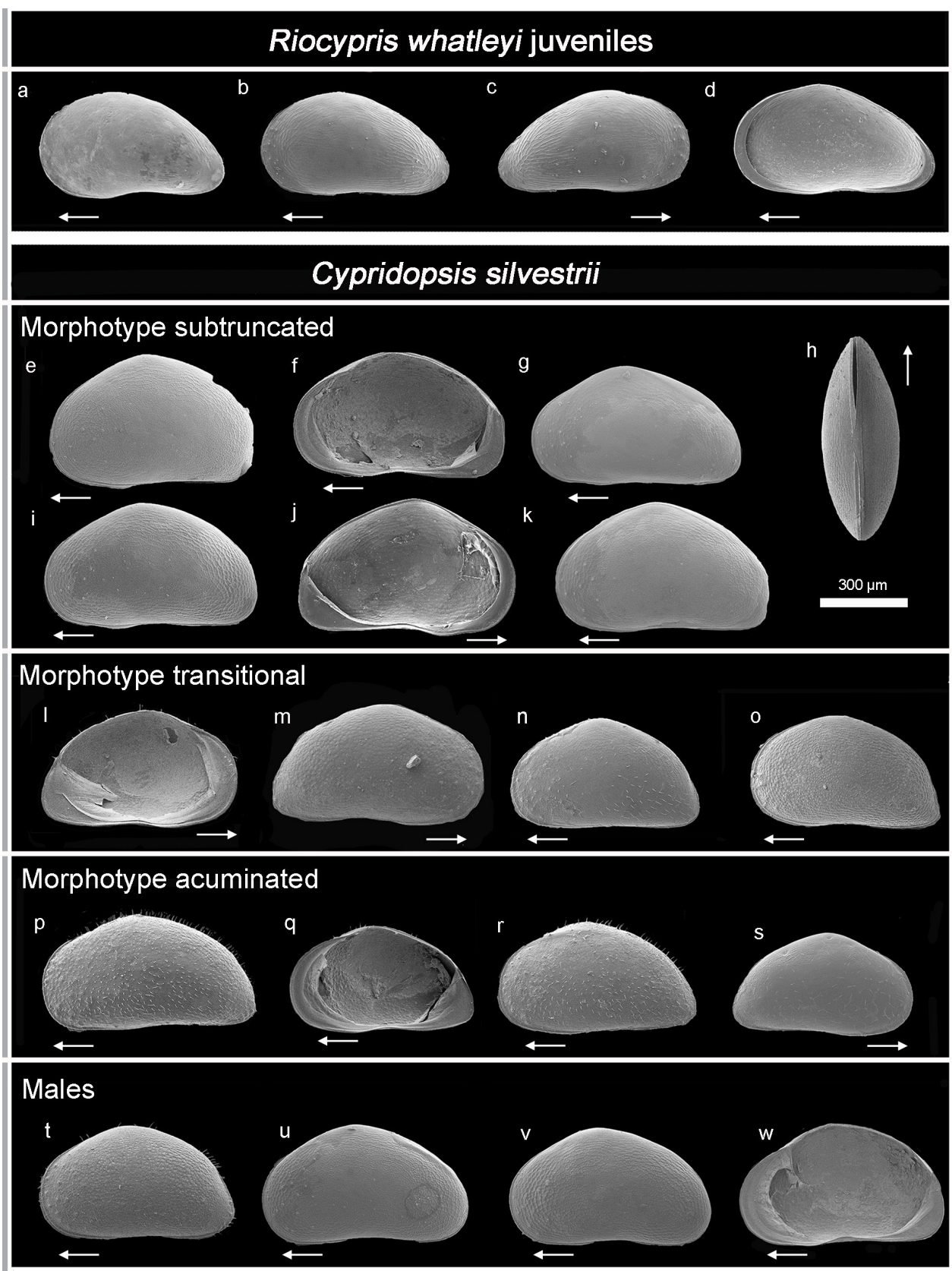

Figure 3. SEM photographs of $R$. whatleyi juvenile from Lake ET and $C$. silvestrii from different localities showing its morphological variability. Figs a) to d): $R$. whatleyi juveniles. External lateral view of a), b) left valves, c) right valve and d) internal view of a right valve. Figs. e) to s): female valves of $C$. silvestrii. Figs. e) to k): "Subtruncated" morphotype. e) External view of left valve from ES, f) internal view of right valve from ES, g) external view of left valve from Pet, h) carapace in ventral view from LE (originally described as E. cecryphalium), i) external and j) internal view of left valve from LE and k) external view of left valve from Cha. Figs. l) to o): "Transitional" morphotype. l) Internal view of left valve from ET, external view of $m$ ) right valve from $L P, n$ ) left valve from CM and o) left valve from L3L. Figs. p) to s): "Acuminated" morphotype. p) External view of left valves from Cha, q) internal view of right valve from ES, $r$ ) external view of left valve from CVO and $s$ ) external view of right valve from MTB. Figs. t) to $w$ ): males of $C$. silvestrii. Left valves in external view from t) ET, u) Cha, v) LE and w) internal view of a right valve from ES. Arrows indicate the anterior part. Abbreviations of sites are given in Supplementary Material Table SI. 
morphotype only was registered in populations with presence of males (Figure $4 \mathrm{a}$ ).

The Nonmetric multidimensional analysis (n-MDS) using fossil and modern specimen's shows that individuals recovered from Quaternary sediments are similar to modern acuminated and transitional morphotypes (Figure 5). Holocene specimens from Lake ET (ETC) display a broad overlap with modern specimens from the same lake characterized by transitional valve shapes. Fossil valves from Lake LJ (LJC), Cari-Laufquen Grande (CLG-5b) and the Maquinchao River (LGW and MO) also have transitional shapes and are similar to modern specimens from CG and ET lakes, all of them located in Northern Patagonia. Specifically, fossil specimens from Lake Cari-Laufquen Grande (CLG-5b) display triangular shapes and are more similar to those from Lake ET, with the exception of the levels corresponding to 2580, 2500, 1749 a)

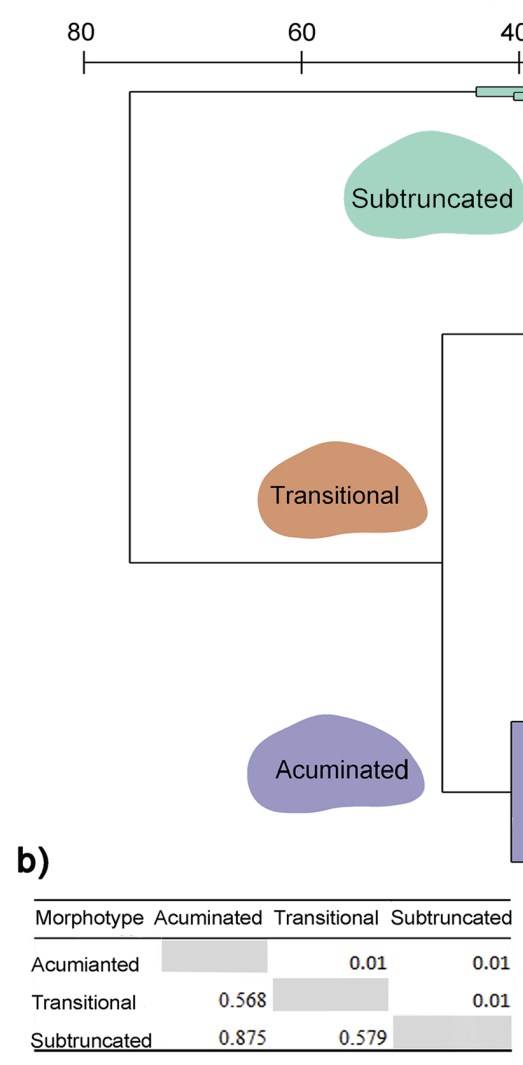

c)

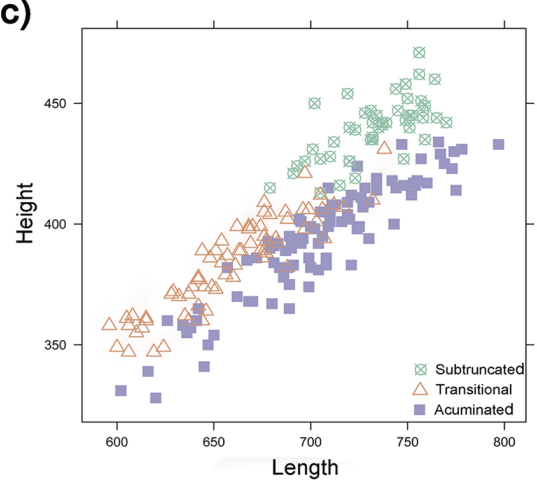

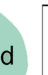

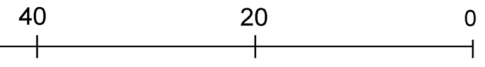

$+\underset{+1}{2+1}$
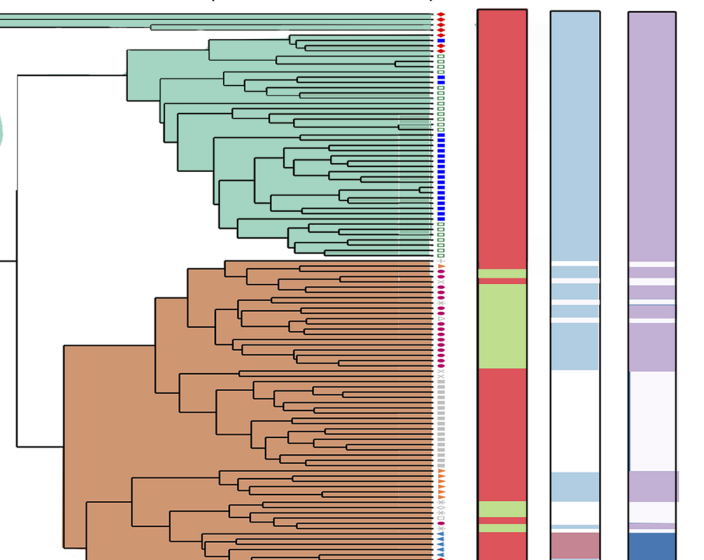

Figure 4. Results of morphometric analysis performed on 216 valves of adult $C$. silvestrii from modern sites. Males were removed from the analyses. a) Dendrogram of cluster analysis based on the dissimilarity matrix in "normalized area" modern, with superimposition of the reconstructed mean shape outline of each cluster or morphotype. Colour symbols and bars on the right side of the figure indicate: 1-Sites where each valve was collected, 2- Region, i.e. North Patagonia or South Patagonia, where each site is located, 3 Males occurrence in the sample and 4- inferred reproduction mode for each specimen (see Table 1), b) One-Way ANOSIM for the shape differences between morphotypes. Values below the diagonal correspond to the ANOSIM's R-statistic values and values above the diagonal correspond to $p$-values and c) Cross plot of height $\sim$ length of the three morphotypes. Abbreviations of sites are given in Supplementary Material - Table SI. 
and 1740 cal. yr BP that are characterized by acuminated shapes. Specimens from cores from the more southernmost sites such as Lago Cardiel (CAR 99-7P, CAR 99-9P and CAR 98-2) and Laguna Carmen (LCTF2) show a boarder shape variability. Most fossil valves from Lago Cardiel have shapes similar to modern individuals from the L3L pond near Lago Cardiel. However, specimens from the base of core CAR 99-7P (15,665 cal. yr. BP) and from Holocene sediments from cores CAR 999P and CAR 98-2 exhibit a broad overlap with modern acuminated individuals from Lake ES. LCTF2 core, comprise acuminated individuals similar to Late Pleistocene valves from core CAR 99-7P and modern specimens from Lake ES, except for specimens from 3150, 2100 and 1500 cal. yr BP, which show a broad overlap with modern forms from Lake ET characterized by transitional shapes.

\section{Reproduction modes and sexual dimorphism}

Seven sites with living specimens of $C$. silvestrii included both males and females, suggesting sexual or mixed reproduction (Table I). Valves display a moderate sexual dimorphism degree, females (Figure 3e to s) have subtruncated or acuminated posterior margins, whereas the posterior part of males is more rounded (Figure 3t to $w$ ). The $R$ value (ANOSIM, R > 0.5) from each site confirms these valve shape differences between sexes (see Supplementary Material - Table SIII for more details). However, valve size differences between sexes were subtle, significant length differences between males and females were only detected at LE and Cha sites, where males were shorter than females (Mann-Whitney U test, LE site: $Z_{\text {adj }}=2.20 P=0.03$; Kruskal-Wallis test, Cha site: $\mathrm{H}_{2,65}=37.42, \mathrm{P}<0.001$; Supplementary Material - Figure S2). In relation

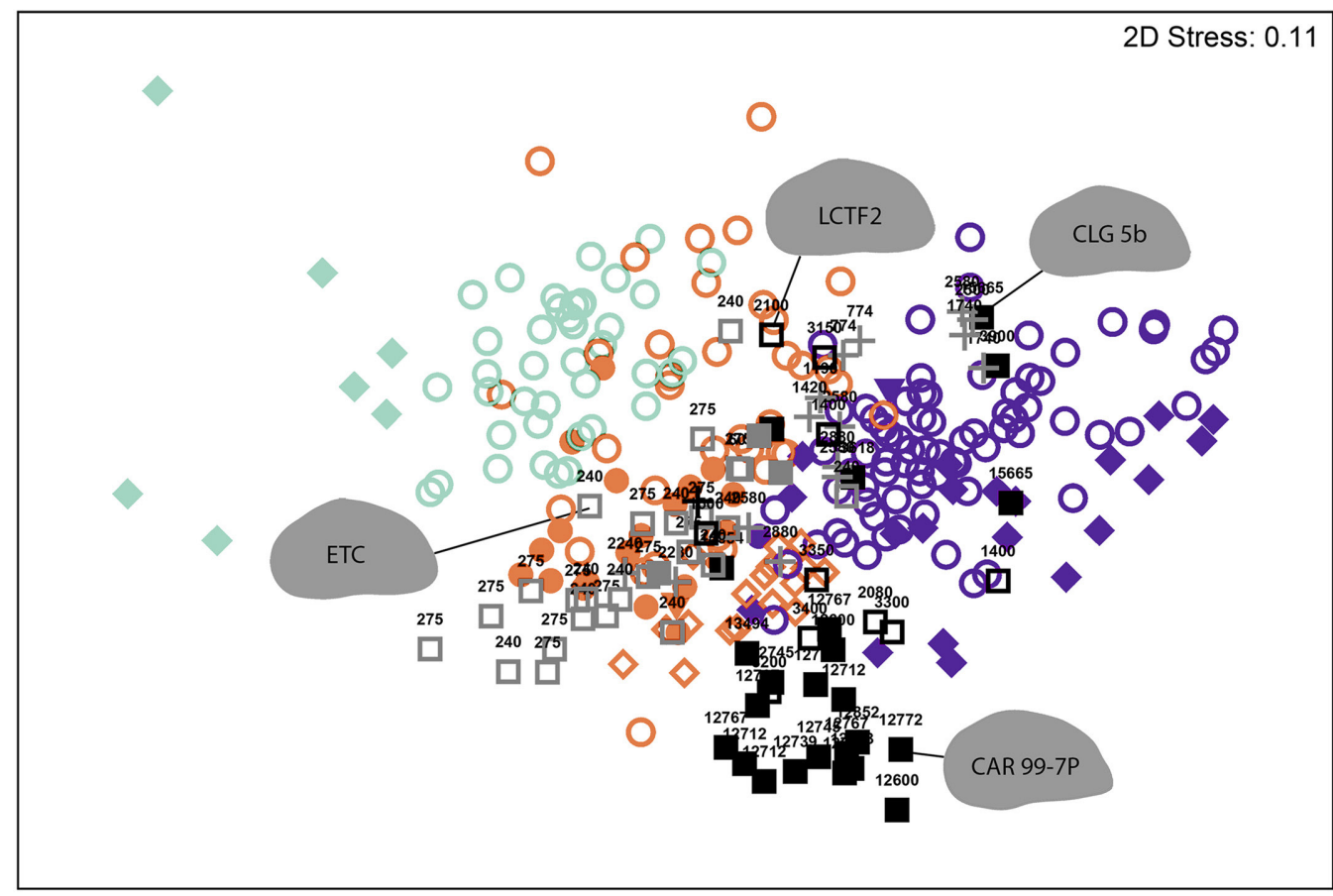
Cores
$\square$ ETC
+ CLG-5b
+ LJC
Maquinchao river cores
(MO and LGW)
Lago Cardiel cores
(CAR 99-7P, CAR 99-9, CAR 98-2)
LCTF2
Modern sites
- ET
$\nabla C G$
$\checkmark \mathrm{ES}$
$\diamond \mathrm{L} 3 \mathrm{~L}$
Morphotypes
O Modern Acuminated
specimens
Modern Transitional
specimens
Modern Subtruncated

Figure 5. Non-metric Multidimensional Scaling (n-MDS) plot showing the shape dissimilarities between digitized outlines (normalized for area) of $C$. silvestrii from Quaternary and modern sites with superimposition of reconstructed outline of selected specimens. Males were removed from the analysis. Numbers indicate calibrated ages of fossils valves. Modern morphotypes were classified according previous cluster analysis. Abbreviations of sites are given in Supplementary Material - Table SI. 
to valve height, females of the subtruncated morphotype from LE pond and Lake Cha as well as transitional morphotypes from Lake ET were greater than males (Mann-Whitney $U$ test, LE site: $Z_{\text {adj }}=4.02 \mathrm{P}<0.001$; Kruskal-Wallis test, Cha site: $H_{2,65}=37.43, P<0.001$, ET site $H_{2,40}=7.46, p=$ 0.003; Supplementary Material - Figure S2).

Three living populations in the most austral portion of the study area (Bo, CVO and MTB sites) consisted of all-female individuals suggesting parthenogenetic reproduction. In these populations, females of the acuminated morphotype are dominant. However, populations with males indicating a sexual reproduction also included females of the three morphotypes. Nevertheless, subtruncated individuals were found exclusively in populations with males (sexual females) (Table I and Figure 4a). Therefore, populations (ES, Cha and GM sites) with males and coexistence of two female morphotypes, i.e. acuminated and subtruncated (Table I), would suggest a mixed reproduction mode, in which there is a co-occurrence of both sexual (subtruncated females) and parthenogenetic (acuminated females) populations (Figure 4a). Moreover, the sex ratio highly biased in favour of females is coherent with this type of reproduction (Table I).

\section{Distribution, environmental and climatic preferences of $C$. silvestrii and its morphotypes} Cypridopsis silvestrii has a large modern distribution in both northern and southern Patagonia, ranging from latitude 40은 to 510 S and from longitude 68은 to 73 - W. This species was found in $24 \%$ of the sites containing ostracods in Patagonia ( $n=140$ ), including temporary ponds and permanent lakes but mainly in lentic environments (Figure 1). Living specimens were recorded in 24 out of the 38 sites with C. silvestrii occurrence and displaying higher tolerance and $\mathrm{ETI}$ values (>0.4) for variations in local environments and climatic variables (Table II).

PCA results show the main environmental and climatic gradients of sites where morphotypes were identified (Figure 6 and

Table I. Morphotype, sex ratio (male:female) and reproduction mode information on 10 living populations of $C$. silvestrii. Abbreviations of sites are given in Supplementary Material - Table SI.

\begin{tabular}{|c|c|c|c|c|c|c|}
\hline Site Code & Acuminated & q Transitional & Subtruncated & $\sigma^{\lambda}$ & Sex ratio & Reproduction \\
\hline ET & & $x$ & & $x$ & $28: 27$ & Sexual \\
\hline LE & & & $x$ & $x$ & $19: 10$ & Sexual \\
\hline CM & & $x$ & & $x$ & $8: 2$ & Sexual \\
\hline Pet & & & $x$ & $x$ & $1: 1$ & Sexual \\
\hline ES & $x$ & & $x$ & $x$ & $36: 6$ & Mixed \\
\hline Cha & $x$ & & $x$ & $x$ & $204: 53$ & Mixed \\
\hline GM & $x$ & & $x$ & $x$ & 3:1 & Mixed \\
\hline Bo & $x$ & & & & $0: 23$ & Parthenogenesis \\
\hline Cvo & $x$ & & & & $0: 72$ & Parthenogenesis \\
\hline MLB & $x$ & & & & $0: 11$ & Parthenogenesis \\
\hline
\end{tabular}


Supplementary Material - Table SIV). The first two dimensions of the PCA accounted for $86 \%$ of the total observed environmental and climatic variance. PC 1 (48\%) is positively correlated with electrical conductivity and negatively correlated with wind. Therefore, this axis separates quite well the sites with higher electrical conductivity and lower wind values, mostly located in northern Patagonia (e.g. ET, CG, Di, LP), from sites with lower conductivity and higher wind values, located in southern Patagonia (e.g. Es, Cha, Bo, EN, L3L). PC 2 (38 \%) is positively correlated with altitude but Bio 15, MAP and MAT are also related with this axis. PC 2 provides a good division between southern Patagonia sites from the Lake Buenos Aires Plateau (i.e. ES, Cha, Pet, GM and Bo), Strobel Plateau (i.e. CM, PO, CVO, L6L, Mar 4, EN and MTB) and lowlands near Lago Cardiel (i.e. TPD, L3L, MC, MC01 and BS) because they are located on an altitudinal gradient (Figure 1 and 6). In relation to northern Patagonia, Lake ET has the highest altitude with higher values of Bio 15 and MAP, whereas CG, NE, LP and Di sites are located at lower altitudes and are characterized by lower Bio 15 and MAP values.

The acuminated and transitional morphotypes are not clearly arranged in groups in the biplot of the PCA, indicating that they occur across a wide environmental gradient (Figure 6). The subtruncated morphotype seems to be an exception, because it occurs in sites from the Buenos Aires Plateau (ES, Cha, Pet and GM) and the Strobel Plateau (LE), all of them characterized by lower conductivity and MAT values as well as high wind speed and Bio 15 values. Estimated species optimum (uk) and tolerance levels ( $t k)$, based on the weighted averaging values, also show high tolerance values to different environmental and climatic variables for C. silvestrii transitional and acuminated morphotypes, but a narrow tolerance index for the subtruncated morphotype (Table II).
The subtruncated morphotype has the lowest optimum values for conductivity $\left(372 \mu \mathrm{S} \mathrm{cm}{ }^{-1}\right)$ and MAT $\left(5^{\circ} \mathrm{C}\right)$, and the highest optimum value for wind speed $\left(8.6 \mathrm{~m} \mathrm{~s}^{-1}\right)$.

\section{DISCUSSION}

\section{Morphological tools for species identification}

This study provides tools to differentiate between Cypridopsis silvestrii and juveniles of Riocypris whatleyi (previously known as Eucypris fontana in Patagonia). Both taxa were difficult to separate by hard parts observation only. The small size of both species has caused difficulties in the identification of specimens from Quaternary sediments and, especially in Lake El Toro, where these taxa have coexist (Supplementary material - Table SI). The morphological analyses demonstrated that $R$. whatleyi juveniles have a more acuminate posterior area and a different surface ornamentation than adult valves of C. silvestrii. These shape differences could be attributed to the development of reproductive structures in adults of $C$. silvestrii. In most podocopids, the anterior part of the valve has a shape similar to the adult from the beginning of development, but the posterior part is the one that undergoes the greatest changes due to the addition of appendages and the development of reproductive structures (Baltanás et al. 2000, Meisch 2000). Moreover, further evidence showed that $C$. silvestrii exhibits an extensive valve morphological variability. In many paleoenvironmental studies involving ostracods, the evolution of ecological characteristics over time are reconstructed from data based on current species ecologies, therefore accurate species identification is mandatory and will allow better inferences of environments changes (Karanovic \& Brandão 2016). In this study, the use of geometric morphometric techniques shows that the shape comparison of the posterior part 
Table II. Number of occurrences $(N)$, optima $\left(u_{k}\right)$ and tolerances $\left(t_{k}\right)$ for environmental and climatic variables of $C$. silvestrii and its morphotypes.

\begin{tabular}{|c|c|c|c|c|c|}
\hline \multicolumn{2}{|c|}{$\mathrm{N}$ and variable } & \multirow{2}{*}{$\begin{array}{c}\text { Cypridopsis silvestrii } \\
24\end{array}$} & \multirow{2}{*}{$\frac{\text { "Subtruncated" }}{5}$} & \multirow{2}{*}{$\begin{array}{c}\text { "Transitional" } \\
7\end{array}$} & \multirow{2}{*}{$\begin{array}{c}\text { "Acuminated" } \\
11\end{array}$} \\
\hline $\mathbf{N}$ & & & & & \\
\hline \multirow{3}{*}{$\begin{array}{l}\text { Electrical } \\
\text { conductivity } \\
\left(\mu \mathrm{S} \mathrm{cm}^{-1}\right)\end{array}$} & $u_{k}$ & 2331 & 372 & 3465 & 979 \\
\hline & $t_{k}$ & 5274 & 164 & 8696 & 2531 \\
\hline & ETI & 0.6 & 0.1 & 1 & 0.9 \\
\hline $\mathbf{N}$ & & 17 & 5 & 7 & 11 \\
\hline \multirow{3}{*}{$\mathrm{pH}$} & $u_{k}$ & 8.9 & 8.8 & 9.1 & 8.8 \\
\hline & $t_{k}$ & 0.7 & 0.6 & 0.5 & 0.9 \\
\hline & ETI & 0.6 & 0.4 & 0.6 & 0.9 \\
\hline $\mathbf{N}$ & & 14 & 4 & 6 & 10 \\
\hline \multirow{3}{*}{$\begin{array}{l}\text { Dissolved oxygen } \\
\qquad\left(\mathrm{mg} \mathrm{L}^{-1}\right)\end{array}$} & $u_{k}$ & 10.7 & 10.3 & 10.5 & 10.4 \\
\hline & $t_{k}$ & 1.6 & 0.2 & 1.6 & 0.8 \\
\hline & ETI & 0.4 & 0.1 & 0.8 & 0.8 \\
\hline $\mathbf{N}$ & & 17 & 5 & 7 & 11 \\
\hline \multirow{3}{*}{$\begin{array}{c}\text { Water } \\
\text { temperature } \\
\left({ }^{\circ} \mathrm{C}\right)\end{array}$} & $u_{k}$ & 12.0 & 11.7 & 11.8 & 11.8 \\
\hline & $t_{\mathrm{k}}$ & 3.2 & 2.8 & 3.5 & 3.8 \\
\hline & ETI & 0.7 & 0.7 & 0.8 & 1.0 \\
\hline $\mathbf{N}$ & & 38 & 5 & 14 & 15 \\
\hline \multirow{3}{*}{$\begin{array}{l}\text { Wind speed } \\
\qquad\left(\mathrm{m} \mathrm{s}^{-1}\right)\end{array}$} & $u_{k}$ & 7.2 & 8.6 & 7.4 & 8.3 \\
\hline & $t_{\mathrm{k}}$ & 1.2 & 0.4 & 0.9 & 0.8 \\
\hline & ETI & 0.7 & 0.2 & 0.8 & 1.0 \\
\hline \multirow{3}{*}{$\begin{array}{l}\text { MAT } \\
\left({ }^{\circ} \mathrm{C}\right)\end{array}$} & $u_{k}$ & 6.3 & 5.0 & 7.8 & 5.7 \\
\hline & $t_{k}$ & 1.8 & 1.5 & 1.3 & 1.8 \\
\hline & ETI & 0.7 & 0.4 & 0.6 & 1.0 \\
\hline \multirow{3}{*}{$\begin{array}{l}\text { MAP } \\
(\mathrm{mm})\end{array}$} & $u_{k}$ & 221 & 206 & 186 & 197 \\
\hline & $t_{k}$ & 66 & 36 & 48 & 38 \\
\hline & ETI & 0.8 & 0.3 & 1.0 & 1.0 \\
\hline \multirow{3}{*}{ Bio 15} & $u_{k}$ & 31.5 & 29.6 & 27.2 & 30.3 \\
\hline & $t_{k}$ & 7.7 & 2.5 & 6.0 & 3.3 \\
\hline & ETI & 0.7 & 0.3 & 1.0 & 0.9 \\
\hline
\end{tabular}

MAT: mean annual temperature, MAP: mean annual precipitation, Bio 15: precipitation seasonality (CV). 
of the valves with the examination of the surface ornamentation could serve as determinant factors to achieve an effective differentiation and identification of these taxa, especially when soft parts are not available.

Cypridopsis silvestrii and Eucypris cecryphalium were previously misidentified because they are similar in valve shape (Ramón-Mercau et al. 2012, Pérez et al. 2019). In this work, valve shape of E. cecryphalium holotype specimens from LE pond were characterized as "subtruncated" (Figure 3i and j) and were analogous to four other populations (ES, CHA, GM y Pet) from southern Patagonia (Figure $3 \mathrm{e}, \mathrm{f}, \mathrm{g}, \mathrm{k}$ ). In addition, the uropodal ramus flagelliform and the morphology of the hemipenis of E. cecryphalium specimens from LE correspond to the holotype of $C$. silvestrii from ET and ES lakes. Based on these sets of observed morphological characters we propose that specimens from LE, previously described as E. cecryphalium, actually belong to $C$. silvestrii. In a previous taxonomic study of $C$. silvestrii two main shapes where described, females from the oligohaline Lake ES with a more acuminated postero-dorsal margin that females from Lake ET characterized by mesohaline waters (Pérez et al. 2019). In this work, three morphotypes of C. silvestrii are described: (1) "acuminated" that includes holotypes valves from Lake ES; (2) "transitional" that comprises holotype valves from Lake ET; and (3) a new "subtruncated" morphotype that encompasses holotype valves from LE pond (Figure 3, e-k). Even though the last one shows an ornamentation pattern and valve length similar to the acuminated or transitional morphotypes, which can lead to confusion, it has a posterior valve area more subtruncated and a more distinct ornamentation.

\section{Distribution patterns and ecological preferences of $C$. silvestrii}

Despite the growing number of investigations carried out during the last few decades, several aspects dealing with ostracods in Patagonia remain unexplored. Thus, our results contribute to increase the existing knowledge of taxonomy, morphological patterns, ecology and distribution

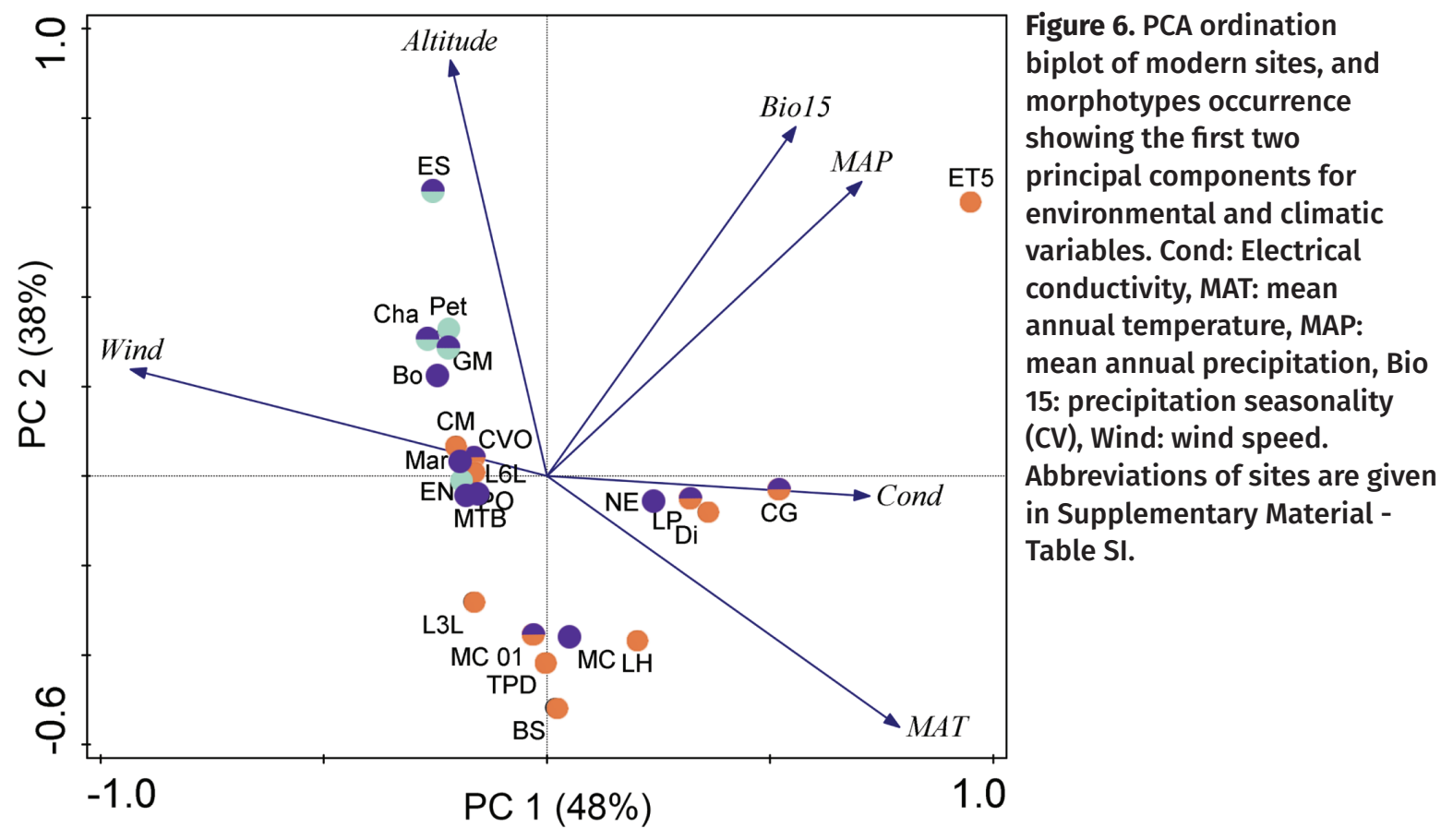


of species that are still poorly known. Cypridopsis silvestrii was highly tolerant to environmental and climatic conditions investigated, however was found living in stagnant waters in both permanent and temporary environments with preference for oligohaline to mesohaline waters (2331 $\pm 5274 \mu \mathrm{S} \mathrm{cm}^{-1}$ see Table II). Accordingly, C. silvestrii was more evenly distributed and very abundant in southern Patagonia (e.g. EN, L3L, ES, see Supplementary Material - Table SI) where aquatic environments are characterized by lower conductivities and windy climate. However, in the North Patagonia, where sampled lakes were characterized by higher conductivity, this species was found in temporary and more saline waters, as Lake ET. Previous taxonomic studies of $C$. silvestrii also pointed out its remarkable tolerance to high conductivity and its preference for alkaline and well oxygenated waters (Pérez et al. 2019). Therefore, this significant tolerance to environmental factors, particularly conductivity $\left(78-42400 \mu \mathrm{S} \mathrm{cm} \mathrm{cm}^{-1}\right.$ ) and water temperature $\left(4-21^{\circ} \mathrm{C}\right)$, might explain why it is one of the most abundant ostracod species present in lacustrine records from Patagonia since the Late Pleistocene (Figure 1).

\section{Morphological variability of modern $C$. silvestrii across spatial scales}

The results of this study provide further evidence that $C$. silvestrii exhibits extensive morphological variability along a broad geographic, climatic and environmental gradient. The geographical range of distribution of modern $C$. silvestrii in Patagonia comprised an extensive area of about $400,000 \mathrm{~km}^{2}$, where the latitudinal range was associated with higher wind speed and lower MAT, and the longitude range was mainly linked to differences in MAP and electrical conductivity of host waters. The phenotype is a product of the interaction between genotype and environment, and environmental heterogeneity is an important driver of biological adaptation (Schlichting \& Pigliucci 1998). However, our results show that morphological differences between populations of $C$. silvestrii could not be clearly attributed to a particular environmental or climatic factor and even morphologically dissimilar forms, such as acuminated and subtruncated morphotypes, were found living together on the same environment (Figure 6). Although it is important to note that even the transitional morphotype had its optimum in waters with higher conductivity values $\left(u_{k}=\right.$ $3465 \mu \mathrm{S} \mathrm{cm}^{-1}$ ) than the acuminated morphotype $\left(u_{k}=979 \mu \mathrm{cm}^{-1}\right)$, both forms were widely distributed in northern and southern Patagonia and occurred under a variety of environmental conditions. Nevertheless, the distribution of the subtruncated morphotype was apparently confined to southern Patagonia and therefore was associated with lower conductivity waters $\left(u \mathrm{k}=372 \mu \mathrm{S} \mathrm{cm}^{-1}\right)$ as well as cold and windy conditions (Figure 1 and 6). Probably due to these hydrological preferences, transitional morphotypes were mainly associated with R. whatleyi and Limnocythere rionegroensis, whereas acuminated and subtruncated shapes, common in southern Patagonia, mostly occurred together with Newnhamia patagonica, Eucypris virgata and Limnocythere patagonica. Although further studies of Patagonian lakes should obtain more environmental and morphological data of this paleo-indicator species, these results provide additional evidence to improve the environmental and climatic interpretation of extant and fossil ostracod assemblages.

\section{Sexual dimorphism and reproduction modes}

According to the description of the sexual dimorphism of living C. silvestrii from Lake ET (Pérez et al. 2019), males from other localities also had a more rounded posterior area than females (Figure $3 u-w)$. This was especially 
noticeable in populations with subtruncated females (Supplementary Material - Table SIII). Cypridopsis silvestrii belongs to the Cyprididae, a family that harbours many species with either fully asexual, fully sexual or mixed modes of reproduction (Horne et al. 1998, Martens et al. 2008). Living populations of exclusively females, suggesting fully parthenogenetic reproduction, had individuals with the posterior valve acuminated, whereas sexual populations tended to have females with a subtruncate posterior margin. Interestingly, a few southern Patagonian populations had two well-separated shape clusters of females, i.e. acuminated and subtruncated, with one type of males and a sex ratio highly biased in favour of females (Table 1). Large excesses of numbers of females are common in mixed populations of ostracods (Chaplin 1993). This fact could point towards a mixed reproduction mode for $C$. silvestrii, where both sexual (diploid) and asexual (di- or triploid) females coexist. According to the $C$. silvestrii morphological pattern, likely parthenogenetic females are linked to acuminated shapes, whereas sexual females are more subtruncated in the posterior area (Figure 4a). Previous studies similarly identified recognizable morphological differences among females related to contrasting reproductive modes in some species (Bellavere et al. 2002, Rossi et al. 2007, Wrozyna et al. 2014). Consequently, the high morphological disparity in C. silvestrii seems to be multi-causal. A more detailed and comparative analysis of the variability of their soft parts, along with DNA analysis, might provide additional data that could help to clarify the mechanisms ruling the observed valve shape variations as well as the mixed reproductive mode and ploidy level of this species.

\section{Morphological variability across temporal scales}

Cypridopsis silvestrii has occurred in Patagonia since the Late Pleistocene, and the geographical range overlapped with that of their modern representatives (Figure 1, square and circle symbols). However, temporal differences in the distribution of $C$. silvestrii morphotypes was identified (Figure 5). Ecological and microevolutionary processes are expect to be responsible for the observed morphological diversity (Baltanás \& Geiger 1998, lepure et al. 2008). The available data show that the modern assemblage includes a greater diversity of shapes, whereas the fossil cluster covers only acuminated and transitional shapes (Figure 5). Thus, these results indicate that lineages of acuminated or transitional morphotypes might be older than the subtruncated morphotypes. However, there is a lack of sedimentary cores from the western Plateau area, where this morphotype is currently found (Figure 1), highlighting the need for further sampling in these poorly explored regions of Patagonia. Populations colonize new habitats, especially when they are able to distribute along broad environmental gradients. This can generate the presence of differentiated forms, genetic diversity or even speciation events (Martens 1998, Wrozyna et al. 2018a). According to previous studies about reproductive strategies (e.g. Chaplin et al. 1994), the mixed reproductive mode of $C$. silvestrii and the presence of parthenogenetic lineages, which likely have desiccation-resistant eggs, would confer efficient dispersal capabilities to colonize new habitats. Thus, the latter can possibly explain its extensive actual distribution as well as its morphological variability.

We also found valve shape differences between fossil records. In general, fossil specimens were similar to actual individuals in the same lake or a nearby one (Figure 1 and 5). This fact indicates a possible funder effect accompanied by successive morphological separation from other populations. However, specimens from Lago Cardiel (CAR 99 7P, CAR 99 
9P and CAR 98-2) and Laguna Carmen (LCTF2) displayed a remarkable shape variability. Few acuminated valves at the base of CAR 99 7P and at 13.6 cal kyr BP might be the result of variable salinity conditions during the Late Pleistocene. Conversely, after the disappearance of $C$. silvestrii around $12.5 \mathrm{cal}$ kyr BP, coinciding with sensible hydrological changes in the lake, the isolated and low abundance of acuminated $C$. silvestrii during the Late Holocene (Ramos et al. 2019) likely suggests a new colonization event. Furthermore, more acuminated valves recovered at 3.1, 2.1 and 1.5 cal kyr BP in core LCTF2 coincided with some oligohaline pulses (Borromei et al. 2018). This also may suggest an ecophenotypic response or change in mode of reproduction towards parthenogenesis. At short time scales, factors such as conductivity, temperature and photoperiod affecting phenotypic valve traits are easier to detect, but over longer time periods, more complex microevolutionary processes are also involved (Roberts et al. 2002). Therefore, the low-resolution morphological data provided by fossil records do not allow more detailed analysis to detect the impact of environmental changes on the phenotypic variability of $C$. silvestrii.

\section{CONCLUSIONS}

Our results confirm the need of studying a large number of samples covering a broad geographic, environmental and temporal scale. This is fundamental to characterize a given ostracod species and obtain more information about the diverse factors influencing their morphological variations. Morphometric analysis allows discriminating between morphological similar taxa i.e. C. silvestrii and R. whatleyi juveniles, providing a tool for the correct taxonomic identification and to distinguish between juveniles and adults. These outcomes have substantial implications when estimating biodiversity and environmental reconstructions.
Additionally, improving the knowledge of the morphological variability, ecological requirements and geographical distribution of $C$. silvestrii provides much needed information to be used as a proxy in paleolimnological studies. These results also enhance our understanding of the morphological variations in this species and set the ground for further taxonomic and molecular studies.

\section{Acknowledgments}

The authors wish to thank all team members of the Patagonian Lake Drilling Project (PATO/PaLaTra) for providing several Quaternary and modern samples. We also express our gratitude to the workers and owners of properties we visited during sampling. We are grateful to Matías Millerón (INIBIOMA) for his help with the construction of the map figure and Laura Zalazar (INIBIOMA) for obtaining the climatic data. We thank P. Troyon and M. Corte of the Caracterización de Materiales department, Centro Atómico Bariloche, for their support with SEM photographs. We are grateful to three anonymous reviewers for their constructive comments that improved the manuscript. This study was funded by the Consejo Nacional de Investigaciones Científicas y Técnicas (CONICET), projects PIP112-20080100819, 2013-2015-00021 and the Agencia Nacional de Promoción Científica y Tecnoógica (ANPCyT), projects PICT 2010-0082 and 2014-1271.

\section{REFERENCES}

ADAMS DC, ROHLF FJ \& SLICE DE. 2004. Geometric morphometrics: ten years of progress following the 'revolution.' Ital J Zool 71:5-16.

AGUIRRE ML, RICHIANOS, ÁLVAREZA \& FARINATI EA. 2015. Reading shell shape: implications for palaeoenvironmental reconstructions. A case study for bivalves from the marine Quaternary of Argentina (south-western Atlantic). Hist Biol 28: 753-773.

BALTANÁS A \& GEIGER W. 1998. Intraspecific morphological variability: morphometry of valve outlines. In: MARTENS $K(E d)$, Sex and parthenogenesis: evolutionary ecology of reproductive modes in non-marine ostracods. Leiden: Backhuys Publishers, p. 127-142.

BALTANÁS A, OTERO M, ARQUEROS L, ROSSETTI G \& ROSSI V. 2000. Ontogenetic changes in the carapace shape of the non-marine ostracod Eucypris virens (Jurine). Hydrobiologia 419: 65-72. 
BAYER MS, MORSAN E, GORDILLO S \& MORAN G. 2016. Form changes in Amiantis purpurata (Bivalvia, Veneridae) shells over the past 100,000 years in North Patagonia (Argentina). J Mar Biol Assoc United Kingdom 96: 1243-1250.

BELLAVERE C, BENASSI G, CALZOLARI M, MEISCH C, MCKENZIE KG \& ROSSI V. 2002. Heterocypris (Crustacea, Ostracoda) from the Isole Pelagie (Sicily, Italy): the coexistence of different morphotypes. Ital J Zool 69: 53-57.

BORROMEI AM ET AL. 2018. Late Holocene wet/dry intervals from Fuegian steppe at Laguna Carmen, southern Argentina, based on a multiproxy record. Palaeogeogr Palaeoclimatol Palaeoecol 499: 56-71.

CHAPLIN JA. 1993. The local displacement of a sexually reproducing ostracod by a conspecific parthenogen. Heredity 71: 259-268.

CHAPLIN JA, HAVEL JE \& HEBERT PD. 1994. Sex and ostracods. Trends Ecol Evol 9: 435-439.

CLARKE KR \& WARWICK RM. 2001. Change in marine communities: an approach to statistical analysis and interpretation, $2^{\text {nd }}$ ed., Plymouth: Plymouth Marine Laboratory, $176 \mathrm{p}$.

CLARKE KR \& GORLEY RN. 2006. Primer V. 6: computer program. Primer-E Ltd., Plymouth.

CORONATO AMJ, CORONATO F, MAZZONI E \& VÁZQUEZ M. 2008. The Physical Geography of Patagonia and Tierra del Fuego. In: Rabassa J (Ed), Late Cenozoic of Patagonia and Tierra del Fuego. Amsterdam: Elsevier, p. 13-55.

COVIAGA CA, RIZZO A, PÉREZ AP, DAGA R, POIRÉ D, CUSMINSKY GC \& RIBEIRO GUEVARA S. 2017. Reconstruction of the hydrologic history of a shallow Patagonian steppe lake during the past $700 \mathrm{yr}$, using chemical, geologic, and biological proxies. Quat Res 87: 208-226.

COVIAGA C, CUSMINSKY G \& PÉREZ P. 2018a. Ecology of freshwater ostracods from Northern Patagonia and their potential application in paleo-environmental reconstructions. Hydrobiologia 816: 3-20.

COVIAGA CA, PÉREZ PA, RAMOS LY, ALVEAR P \& CUSMINSKY GC. 2018b. On two species of Riocypris (Crustacea, Ostracoda) from Northern Patagonia and their relation to Eucypris fontana; implications in paleoenvironmental reconstructions. Can J Zool 96: 801-817.

COVIAGA C, CUSMINSKY GC, PÉREZ AP, SCHWALB A, MARKGRAF $\checkmark$ AND ARIZTEGUI D. 2018c. Paleoenvironmental changes during the last 3000 years in lake Cari-Laufquen (Northern Patagonia, Argentina), inferred from ostracod paleoecology, petrophysical, sedimentological and geochemical data. Holocene 28:1881-1893.

CURRY BB. 1999. An environmental tolerance index for ostracodes as indicators of physical and chemical factors in aquatic habitats. Palaeogeogr Palaeoclimatol Palaeoecol 148: 51-63.
CUSMINSKY GC \& WHATLEY RC. 1996. Quaternary non-marine ostracods from lake beds in Northern Patagonia. Rev Española Paleontol 11: 143-152.

CUSMINSKY GC, PÉREZ AP, SCHWALB A \& WHATLEY R. 2005. Recent lacustrine ostracods from Patagonia, Argentina. Rev Española Micropaleontol 37: 431-450.

DANIELOPOL DL, BALTANÁS A, NAMIOTKO T, GEIGER W, PICHLER M, REINA M \& ROIDMAYR G. 2008. Developmental trajectories in geographically separated populations of non-marine ostracods: morphometric applications for palaeoecological studies. Senckenbergiana lethaea 88 : 183-193.

FICK SE \& HIJMANS RJ. 2017. WorldClim 2: new 1 km spatial resolution climate surfaces for global land areas. Int. J. Climatol 37: 4302-4315.

GRIFFITHS HI \& HOLMES JA. 2000. Non-marine ostracods and Quaternary palaeoenvironments (QRA Technical Guide No. 8). London: Quaternary Research Association, $188 \mathrm{p}$.

HORNE DJ, BALTANÁS A \& PARIS G. 1998. Geographical distribution of reproductive modes in living non-marine ostracods. In: Martens K (Ed), Sex and parthenogenesis: evolutionary ecology of reproductive modes in nonmarine ostracods. Leiden: Backhuys Publishers, p. 77-99.

IEPURE S, NAMIOTKO T \& DANIELOPOL DL. 2008. Morphological diversity and microevolutionary aspects of the lineage Cryptocandona vavrai Kaufmann, 1900 (Ostracoda, Candoninae). Ann Limnol - Int J Limnol 44: 151-166.

JUGGINS S. 2017. Rioja: Analysis of Quaternary Science Data, R package version (0.9-21). http://cran.r-project. org/package=rioja.

KARANOVIC I \& BRANDÃO SN. 2016. The genus Polycope (Polycopidae, Ostracoda) in the North Atlantic and Arctic: Taxonomy, distribution, and ecology. Syst Biodivers 14: 198-223.

KILIAN R \& LAMY F. 2012. A review of Glacial and Holocene paleoclimate records from southernmost Patagonia (4955o S). Quat Sci Rev 53: 1-23.

LEPŠ J \& ŠMILAUER P. 2003. Multivariate analysis of ecological data using CANOCO, Cambridge Univ. Press, Cambridge, 269 p.

LINHART J, BRAUNEIS W \& NEUBAUER W. 2007: Morphomatica, version 1.6.0.1. University of Graz, Graz.

MARTENS K, SCHÖN I, MEISCH C \& HORNE DJ. 2008. Global diversity of ostracods (Ostracoda, Crustacea) in freshwater. Hydrobiologia 595: 185-193.

MARTENS K. 1998. Sex and ostracods: a new synthesis. In: Martens K (Ed), Sex and parthenogenesis: evolutionary ecology of reproductive modes in non-marine ostracods. Leiden: Backhuys Publishers, p. 295-232. 
MAZZINI I, GLIOZZI E, ROSSETTI G \& PIERI V. 2014. The Ilyocypris puzzle: A multidisciplinary approach to the study of phenotypic variability. Int Rev Hydrobiol 99: 1-14.

MAZZONI E \& RABASSA J. 2018. Volcanic Landscapes and Associated Wetlands of Lowland Patagonia. Switzerland: Springer International, p. 295.

MEISCH C. 2000. Freshwater Ostracoda of Western and Central Europe, Vol. 8/3. Heidelberg: Spektrum Akademischer Verlg, p. 522.

MEZQUITA F, ROCA JRR, REED JMM \& WANSARD G. 2005. Quantifying species-environment relationships in nonmarine Ostracoda for ecological and palaeoecological studies: Examples using Iberian data. Palaeogeogr Palaeoclimatol Palaeoecol 225: 93-117.

MONFERRAN MD, GALLEGO OF, ASTROP TI \& CABALERI N. 2013. Autecology of Wolfestheria smekali (Spinicaudata) from the Upper Jurassic (Cañadon Asfalto Formation), Patagonia, Argentina. Palaeogeogr Palaeoclimatol Palaeoecol 392: 52-61.

NEUBAUER W \& LINHART J. 2008. Approximating and distinguishing Ostracoda by the use of B-Splines. In: Danielopol DL et al. (Eds), Contribution to Geometric Morphometric. Graz: Karl Franzens Universität, Graz, p 21-42.

PARUELO JM, BELTRAN A, JOBBÁGY E, SALA O \& GOLLUCIO R. 1998. The climate of Patagonia: general patterns and controls on biotic processes. Asoc Argentina Ecol 8: 85-101.

PEARSON RG \& DAWAON TP. 2003. Predicting the impacts of climate change on the distribution of species: are bioclimate envelope models useful? Glob Ecol Biogeogr 12: 361-371.

PÉREZ AP, COVIAGA CA, RAMOS LY, LANCELOTTI J, ALPERIN M \& CUSMINSKY GC. 2019. Taxonomic revision of Cypridopsis silvestrii comb. nov. (Ostracoda, Crustacea) from Patagonia, Argentina with morphometric analysis of their intraspecific shape variability and sexual dimorphism. Zootaxa 4563: 83-102.

R CORE TEAM. 2019. R: A language and environment for statistical computing. R Foundation for Statistical Computing, Vienna, Austria. https://www.R-project.org/.

RAMÓN-MERCAU J, LAPRIDA C, MASSAFERRO J, ROGORA M, TARTARI G \& MAIDANA NI. 2012. Patagonian ostracods as indicators of climate related hydrological variables: implications for paleoenvironmental reconstructions in Southern South America. Hydrobiologia 694: 235-251.

RAMÓN-MERCAU J, PLASTANI MS \& LAPRIDA C. 2014. A review of the genus Limnocythere (Podocopida: Limnocytheridae) in the Pampean region (Argentina), with the description of a new species, Limnocythere cusminskyae sp. nov. Zootaxa 3821: 26-36.

RAMÓN-MERCAU J \& LAPRIDA C. 2016. An ostracodbased calibration function for electrical conductivity reconstruction in lacustrine environments in Patagonia, Southern South America. Ecol Indic 69: 522-532.
RAMOS LY, ALPERIN M, PÉREZ AP, COVIAGA CA, SCHWALB A \& CUSMINSKY GC. 2015. Eucypris fontana (Graf, 1931) (Crustacea, Ostracoda) in permanent environments of Patagonia Argentina: a geometric morphometric approach. Ann Limnol - Int J Limnol 51: 125-138.

RAMOS L, CUSMINSKY G, SCHWALB A \& ALPERIN M. 2017. Morphotypes of the lacustrine ostracod Limnocythere rionegroensis Cusminsky \& Whatley from Patagonia, Argentina, shaped by aquatic environments. Hydrobiologia 786: 137-148.

RAMOS L, ALPERIN M, SCHWALB A, MARKGRAF V, ARIZTEGUI D \& CUSMINSKY G. 2019. Changes in ostracod assemblages and morphologies during lake level variations of Lago Cardiel $\left(49^{\circ} \mathrm{S}\right)$, Patagonia, Argentina, over the last 15.6 kyr. Boreas 48: 746-760.

ROBERTS JH, HOLMES JA \& SWAN AR. 2002. Ecophenotypy in Limnocythere inopinata (Ostracoda) from the late Holocene of Kajemarum Oasis (north-eastern Nigeria). Palaeogeogr Palaeoclimatol Palaeoecol 185: 41-52.

ROHLF FJ. 2010. TpsDig digitize landmarks from image files, scanner, or video, version 2.16. Department of Ecology and Evolution, State University of New York at Stony Brook. http://life.bio.sunysb.edu/morph/.

ROSSI V, GANDOLFI A, BARALDI F, BELLAVERE C \& MENOZZI P. 2007. Phylogenetic relationships of coexisting Heterocypris (Crustacea, Ostracoda) lineages with different reproductive modes from Lampedusa Island (Italy). Mol Phylogenet Evol 44: 1273-1283.

SCHLICHTING CD \& PIGLIUCCI M. 1998. Phenotypic evolution: a reaction norm perspective. Sunderland, MA: Sinauer Associates, $387 \mathrm{p}$.

SCHWALB AJ, BURNS S, CUSMINSKY GC, KELTS K \& MARKGRAF V. 2002. Assemblage diversity and isotopic signals of modern ostracodes and host waters from Patagonia, Argentina. Palaeogeogr Palaeoclimatol Palaeoecol 187: 323-339.

STATSOFT INC. 2004. STATISTICA (data analysis software system), version 7. http://statsoft.com.

VILLALBA R, LARA A, BONINSEGNA JA, MASIOKAS M, DELGADO S, ARAVENA JC, ROIG FA, SCHMELTER A, WOLODARSKY A \& RIPALTA A. 2003. Large-Scale Temperature Changes across the Southern Andes: $20^{\text {th }}$ Century Variations in the Context of the Past 400 Years. Clim Change 59: 177-232.

WEI T \& SIMKO V. 2017. R package "corrplot": Visualization of a Correlation Matrix (Version 0.84). https://github. com/taiyun/corrplot.

WROZYNA C, PILLER WE \& GROSS M. 2014. Morphotypes of Cytheridella ilosvayi (Ostracoda) detected by soft and hard part analyses. Crustaceana 87: 1043-1071.

WROZYNA C, MEYER J, GROSS M, RAMOS MIF \& PILLER WE. 2018a. Definition of regional ostracod (Cytheridella) 
morphotypes by use of landmark-based morphometrics. Freshw Sci 37: 573-592.

WROZYNA C, NEUBAUER TA, MEYER J, RAMOS MIF \& PILLER WE. 2018b. Significance of climate and hydrochemistry on shape variation - a case study on Neotropical cytheroidean Ostracoda. Biogeosciences 15: 5489-5502.

\section{SUPPLEMENTARY MATERIAL}

Table SI. Overview of the occurrences of $C$. silvestrii in Patagonia including information about samples, age, number of valves analysed with Geometric Morphometric techniques, morphotype and species former name.

Table SII. Results of the One-Way ANOSIM for shape differences (expressed by the R statistic values) between left and right valves of females for morphotype and population, respectively. Abbreviations of sites are given in Supplementary Material - Table SI.

Table SIII. Results of the One-Way ANOSIM for the shape differences (expressed by the R statistic values) between males and female, respectively. Abbreviations of sites are given in Table SI.

Table SIV. Summary of the principal component analysis (PCA) results. Abbreviations of sites are given in Supplementary Material - Table SI.

Figure S1. Scheme of the variables measured on each valve and the reconstructed outline (red line) using B-spline outline analyses. v1-v15 = control points along the ventral part of the outline; $\mathrm{m} 1-\mathrm{m} 2$ = control points on the intersection of the axis of minimum moment of inertia and the outline and d1-d15 = control points along the dorsal part of the outline. Figure S2. Boxplots showing the median valve length and height for sexes for each population. Letters indicate significant differences $(p<0.05)$ between pairwise non-parametric comparisons of sex and female morphotypes at each site. Abbreviations of sites are given in Supplementary Material - Table SI.

\section{How to cite}

RAMOS LY, PÉREZ AP, COVIAGA CA, SCHWALB A, ARIZTEGUI D, ALPERIN M \& CUSMINSKY GC. 2021. Morphological diversity and discrimination tools of the non-marine ostracod Cypridopsis silvestrii across temporal and spatial scales from Patagonia. An Acad Bras Cienc 93: e20200635. DOI 10.1590/0001-3765202120200635.
LORENA Y. RAMOS ${ }^{1}$

https://orcid.org/0000-0002-7888-8324

\section{ALEJANDRA PATRICIA PÉREZ ${ }^{1}$}

https://orcid.org/0000-0003-2334-4191

CORINA A. COVIAGA

https://orcid.org/0000-0002-2634-2354

\section{ANTJE SCHWALB ${ }^{2}$}

https://orcid.org/0000-0002-4628-1958

DANIEL ARIZTEGUI ${ }^{3}$

https://orcid.org/0000-0001-7775-5127

MARTA ALPERIN ${ }^{4}$

https://orcid.org/0000-0003-2608-4890

\section{GABRIELA C. CUSMINSKY ${ }^{1}$}

https://orcid.org/0000-0001-5484-5285

${ }^{1}$ CONICET-Universidad Nacional del Comahue INIBIOMA, Quintral 1250, Bariloche, CP 8400, Río Negro, Argentina

${ }^{2}$ Technische Universität Braunschweig, Institute of Geosystems and Bioindication, Langer Kamp 19c, D-38106, Braunschweig, Germany

${ }^{3}$ University of Geneva, Department of Earth Sciences, rue des Maraichers 13, Geneva 1205, Switzerland

${ }^{4}$ Universidad Nacional de La Plata, Catedra de Estadística, Facultad de Ciencias Naturales y Museo, Calle $64 \mathrm{~N}$ 3 (e/Diag. 113 y Bva. 120), La Plata, Argentina

Correspondence to: Lorena Y. Ramos

E-mail: lorenayramos@gmail.com

\section{Author contributions}

LR and PP equally contributed to the manuscript. PP, CC, DA, AS, LR and GC participated in the field campaigns. PP and CC prepared living ostracod material and conducted the ostracod dissections. PP also contributed with principal component analysis. MA supported the statistical analyses. LR performed the statistical and geometric morphometric analyses, wrote the manuscript and all authors commented jointly on the manuscript. GC and PP were in charge of funding acquisition and management.

\section{(cc) BY}

